\title{
Repensar el patriarcado. ¿Más allá de la condición de víctima de la mujer?
}

\section{Lizbeth Sagols}

$\mathbf{N}$ hay ningún país en que las mujeres sean tratadas igual que los hombres. ${ }^{1}$ En efecto, siguen siendo una realidad mundial la "doble jornada", el llamado "techo de cristal", la devaluación económica de los trabajos típicamente femeninos y la escasa participación de las mujeres en los puestos económicos y políticos decisivos. El mínimo indispensable de la igualdad mujeres-hombres en los sueldos y las oportunidades de participación pública, no se ha logrado. Además, en ciertos países (como en México) perduran los feminicidios ${ }^{2}$ y en el mundo entero perduran o han aumentado las violaciones y la violencia física contra las mujeres (en países desarrollados y en vías de desarrollo). En las tendencias fanáticas de los musulmanes impera aún la negativa a ofrecer a las mujeres educación y a concederles libertad sexual: se les niega mostrar la cara y el cuerpo, y si alguna mujer comete adulterio es apedreada en público. Por otra parte, entre los muchos conflictos que ocasiona el cambio climático se ha visto que las mujeres pobres de los países en desarrollo son el sector más afectado, pues se multiplican las dificultades para dar de comer y beber a sus familias y, en consecuencia, crece su pobreza. Salta a la vista que las mujeres no merecen la misma valoración que los hombres, no gozan de las mismas condiciones sociales, se les oprime desde su condición sexual y desde los roles que les ha asignado la sociedad.

No obstante, algunas teóricas feministas se niegan a aceptar que la mujer sea en realidad una víctima del patriarcado: las receptoras de los daños

${ }^{1}$ Paul Ehrlich y Anne Ehrlich, "Can a collapse of global civilization be avoided?", en Proceedings of the Royal Society B, 2013, vol. 280, http//dx.doi.org/10.1098/ rspb.2012.2845, p. 6. Al hablar aquí de "las mujeres" nos referimos al promedio de la población, aunque es obvio que existen ciertas excepciones en algunos de los aspectos nombrados.

${ }^{2}$ Según el Observatorio de Feminicidios en México, la onU registra siete feminicidios al día en este país. Véase http://observatoriofeminicidio.blogspot.mx/2014/11/sabado15-de-noviembre-de-2014.html. 
ocasionados por un trato desigual, injusto e inferiorizante. Después de que en muchos países los derechos de las mujeres han sido protegidos por la ley y después de que se ha dado una creciente inserción activa de ellas en la economía, en la vida cultural y la política (aunque no en puestos decisivos) a muchas intelectuales les incomoda seguir afirmando la existencia del patriarcado y se niegan a aceptar que éste hace de las mujeres sus víctimas. Según este tipo de feministas, los cambios históricos acaecidos han abierto a la mitad femenina de la humanidad múltiples alternativas y seguir afirmando la condición de víctimas es verlas como débiles y contribuir a victimizarlas en vez de liberarlas.

En este artículo, analizo dos ejemplos sobresalientes de tal forma de pensar: los planteamientos básicos de Gerda Lerner expresados en su Introducción a The Creation of Patriarchy, por un lado, y los de Élisabeth Badinter expresados en Hombres-mujeres. Cómo salir del camino equivocado, por el otro -aunque existen muchos más casos. ${ }^{3}$ Mi objetivo es mostrar, con apoyo en la idea del patriarcado como estructura social persistente -idea propuesta por la eticista y ecofeminista estadounidense Karen Warren y por la polémica jurista, también estadounidense, Catharine MacKinnon- que no es favorable negarnos a ver nuestra condición de víctimas del patriarcado, pues tal negación constituye una "ilusión" que desconoce la realidad pasada y presente: ${ }^{4}$ desconoce las determinaciones que nos circundan. Aunque K. Warren pertenece al "feminismo cultural" (centrado en el análisis del "género" y los "marcos

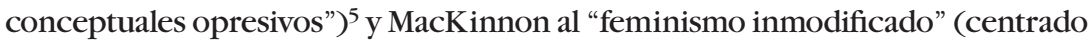
en el abuso del poder masculino sobre el cuerpo y la sexualidad femenina que nos excluye del poder), ambas coinciden en destacar que el patriarcado es

${ }^{3}$ Otro ejemplo es el de la filósofa estadounidense Val Plumwood, quien hace residir el sistema imperante de dominio en el colonialismo y no en el patriarcado, o sea, en la superioridad, no de los hombres sobre las mujeres, sino del hombre blanco, poderoso y colonizador sobre los países en desarrollo. A Plumwood le parece que el patriarcado se reduce a Occidente y que hacer de él un factor histórico universal decisivo conlleva la satanización del hombre, así como la identificación del mal con el macho, y de la mujer con el bien (Val Plumwood y Alicia Puleo, "Introducción", en El ecofeminismo para otro mundo posible. Madrid, Cátedra, 2011). Ante esto, por lo menos, hay que preguntar: ¿entonces no existe el patriarcado de los países musulmanes y en la ortodoxia judía, que pertenecen a Oriente? ¿Cómo reducir el patriarcado a Occidente?

${ }^{4}$ Desde luego que el pensamiento de MacKinnon no se reduce a la que es quizá su afirmación más conocida: "la heterosexualidad, en tanto institución social está fundada en la penetración de la vagina por el pene" (Catharine MacKinnon, Feminismo inmodificado. Discursos sobre la vida y el derecho. Buenos Aires, Siglo XXI, [1987] 2014, p. 86). Dar una importancia exclusiva a esta afirmación resulta en verdad reductivista. El pensamiento de esta filósofa jurista aporta muchos otros aspectos.

${ }^{5}$ Vid. K. Warren, "El poder y la promesa del ecofeminismo", en Margarita M. Valdés, comp., Naturaleza y valor. México, UNAM/FCE, 2005. 
actual y estructural: conforma un horizonte de pensamiento y de conductas de dominio y exclusión de los hombres hacia las mujeres. ${ }^{6}$

\section{Líneas básicas de las propuestas de Gerda Lerner y Élisabeth Badinter}

Para Gerda Lerner, el patriarcado consiste, ante todo, en el "control de la sexualidad femenina y la procreación", 7 o sea, en la formación de la familia patriarcal, lo cual trajo un cambio en las relaciones de parentesco, la economía, la burocracia religiosa y las concepciones cosmogónicas. ${ }^{8}$ Ella reconoce que esto ha traído subordinación y ha convertido a las mujeres en víctimas, pero se opone a pasar de este hecho a la conceptualización "esencial" de ellas "como víctimas", a verlas como inferiores y aceptar que no han contribuido a la formación de la historia de la humanidad. ${ }^{9}$ Para evitar caer en tal concepción, que según ella sería esencialista (aunque no necesariamente es así), ${ }^{10}$ Lerner se esfuerza por demostrar que las mujeres hemos sido siempre actores y agentes históricos; hemos sido parte fundamental de la sociedad y la historia desde antes del surgimiento del patriarcado: en el neolítico, en donde la religión se regía por diosas: símbolo máximo de la fertilidad y la vida. Y aún después del neolítico hemos participado de forma activa en la construcción histórica, ya que en ciertos ámbitos, como el económico, hemos disfrutado de un gran estatus. Uno de los ejemplos que da Lerner para apoyar esto es el caso de Babilonia en donde a pesar del dominio sexual de los hombres "algunas mujeres disfrutaban de una gran independencia económica, numerosos derechos legales y privilegios y ocupaban cargos de importancia". ${ }^{11}$ Por esto, además, es fundamental para el feminismo y el rescate de la mujer, que las mujeres hagan historia de sí mismas. ${ }^{12}$

El periodo del surgimiento del patriarcado que, según Lerner, va del año 3100 al 600 a. C. ${ }^{13}$ no trajo una "derrota" de las mujeres ni las dejó fuera de la

${ }^{6}$ Vid. C. MacKinnon, "Diferencia y dominación: sobre la discriminación sexual", en Feminismo inmodificado. Discursos sobre la vida y el derecho, pp. 57-78.

${ }^{7}$ Gerda Lerner, The Creation of Patriarchy. Nueva York, Universidad de Oxford, 1986, pp. 7-9.

${ }^{8}$ Ibid., p. 7.

${ }^{9}$ Ibid., pp. 5-6.

${ }^{10}$ Decir que alguien está sufriendo no equivale a decir que sea en esencia sufriente.

${ }^{11}$ G. Lerner, op. cit., p. 8.

${ }^{12}$ Ibid., pp. 3-4.

${ }^{13}$ Estas fechas son aproximadas. No todos los estudiosos del patriarcado coinciden con ellas. El estudio más documentado a este respecto es de la arqueóloga Marija Gim- 
historia real, sólo las excluyó del registro y la narración histórica, ya que esta última ha sido elaborada por los hombres. ${ }^{14}$ Dicho de forma sintética, tal exclusión comenzó con la elaboración de los símbolos del cristianismo monoteísta que anuló a las diosas dadoras de vida, sustituyéndolas por el "Señor" y "Dios rey" que engendró a su hijo sin contacto sexual con alguna mujer. Las diosas fértiles del neolítico fueron cambiadas por una única divinidad masculina. Y la sexualidad femenina, sin fines reproductivos, se consideró un símbolo del pecado y el mal. Desde entonces, la mujer quedó en un plano subordinado. Lo que hay que hacer ahora es insertar a las mujeres en el propio patriarcado y demostrar que sí han participado en la historia. Por tanto, la comprensión real, viva, del proceso histórico requiere añadir la historia femenina a la masculina; sólo así lograremos la transformación, la visión de fondo y tridimensional de la historia, en donde se manifiesta que hombres y mujeres hemos jugado papeles de igual importancia. ${ }^{15} \mathrm{Si}$ las feministas ofrecen una visión histórica a partir de los hombres y la exclusión que han hecho de la mitad femenina de la humanidad, están contribuyendo a su desigualdad, exclusión y victimización.

Por su parte, la filósofa francesa Élisabeth Badinter, está preocupada por hacer real el encuentro entre las dos mitades de la humanidad, pues cada vez más, la mayor parte de los hombres y de las mujeres tiene el deseo de vivir juntos y de vivir mejor. ${ }^{16}$ Ante esto, la verdadera tarea evolutiva de la humanidad es fortalecer la igualdad entre los sexos y los géneros, sabiendo que somos diferentes pero sin hacer de la diferencia una esencia. Le preocupa que el feminismo francés contemporáneo haya caído en una trampa mortal: querer conquistar la independencia de la mujer afirmando la diferencia femenina por la supuesta liga de la mujer con la naturaleza gracias al embarazo y el cuidado de los niños. En su opinión, esto ha sido regresivo para la mujer, la ha atado a su rol más conservador y la ha excluido de la productividad económica y la interacción social. El resultado ha sido que las mujeres francesas sean ahora dependientes económicas de sus parejas y corran el peligro de que los hombres se harten de ellas y las abandonen.

Sólo que Badinter mezcla los lúcidos razonamientos anteriores con una oposición a seguir acusando al hombre de violencia patriarcal. Ella sugiere que en los comportamientos de la parte masculina de la humanidad ya no operan del todo los esquemas patriarcales, pues los hombres han cambiado: ellos no

butas que ubica el surgimiento del patriarcado en el milenio IV a. C. con las invasiones de los Kurgans.

${ }^{14}$ G. Lerner, op. cit., p. 8.

${ }^{15}$ Ibid., p. 12.

${ }^{16}$ Élisabeth Badinter, Hombres-Mujeres. Cómo salir del camino equivocado. Buenos Aires, FCE, 2003, p. 121. 
constituyen una entidad inmutable y, al parecer, han evolucionado. ${ }^{17}$ Para Badinter, ha habido un cambio y una diversificación de las masculinidades. No todos los hombres son machos patriarcales desbocados. Por otra parte, las mujeres han dado grandes muestras de ser violentas (Badinter cita ejemplos concretos, históricos, de la vida cotidiana y la vida en pareja. ${ }^{18}$ Destaca así que la violencia es característica de la humanidad entera y no sólo de la parte masculina, por ende, concluye: al quejarse reiteradamente de sufrir violencia, las mujeres se enmascaran a sí mismas y abusan del poder que les han dado las leyes de "sentirse víctima" como si la violencia les fuera ajena.

Desde una visión eurocentrista, incluso concentrada en la realidad francesa -si no es que tan sólo en ciertas capas sociales parisinas-, Badinter considera que el patriarcado ha quedado casi atrás; ya no hay dominio sexual del hombre hacia la mujer ni predominio de la figura paterna, antes bien, las mujeres tienen el poder efectivo de ser dueñas de la reproducción; ellas puede decir: "serás padre sólo si yo lo quiero, cuando yo quiera". ${ }^{19}$ Asimismo, el patriarcado se ha visto muy disminuido porque la mujer tiene dominado al hombre con la amenaza de demandarlo ante los tribunales por el delito de "acoso sexual", apelando a uno o varios de los hechos heterogéneos incluidos bajo la serie: una mirada insistente, el acoso laboral, el acoso sexual, una violación forzada, la seducción fortuita, un mal comentario o un mal tono usado en la casa o en el trabajo. Badinter señala, de forma atinada, que no todos estos hechos pueden ser englobados en la misma categoría y que es preciso distinguir -con claridad y nitidez- entre unos y otros. ${ }^{20}$

Y más allá de esto, le preocupa que la abundancia de leyes a este respecto haya llegado a colocar a las mujeres en el nivel de víctimas complacidas y las haya alejado del compañerismo y la comprensión igualitaria de las relaciones intersexuales. Ver a la mujer como víctima del patriarcado, señala Badinter, es concebirla como una "menor de edad", desconocer su participación responsable e igualitaria en los acontecimientos intersexuales. En el contexto del abuso femenino de las leyes contra los hombres y bajo el concepto y la exigencia de la igualdad interhumana, la idea de que la mujer pueda ser considerada como víctima del patriarcado queda descalificada, incluso ridiculizada: quizá "las mujeres no sean víctimas tan impotentes como les gusta decir". ${ }^{21}$

${ }^{17}$ Ibid., pp. 48-49.

${ }^{18}$ Ibid., pp. 62-75.

${ }^{19}$ Ibid., p. 9.

${ }^{20}$ Ibid., pp. 17-39. A este respecto cabe señalar la falta de claridad que implica que el Código Penal del Distrito Federal de México considere motivo de cárcel o multa para los varones, una "mirada lasciva". http://www.eluniversal.com.mx/notas/841575.html.

${ }^{21}$ É. Badinter, op. cit., p. 124. 


\section{Análisis de las propuestas de Lerner y Badinter}

¿Queda negado el patriarcado y la condición de víctima de las mujeres con los planteamientos anteriores? ¿Podemos desconocer sin más que todos los hechos que nombramos al inicio de este artículo hablan de un grave daño a las mujeres - muchas veces irreparable-y que, por tanto, las deja en condición de víctimas? No creo que pueda procederse de esta manera. Podemos encontrar aquí más bien un razonamiento circular, injustificado, del que pensadoras como Lerner y Badinter no quieren salir, ya que un hecho es ver que alguien es víctima de alguien o algo, y otro caer en la victimización o victimizar a ese alguien: centrar el valor de esta persona en su dolor: "sufre, luego vale", y de ahí pasar a buscar la protección de esta persona a toda costa. De igual modo, un hecho es que el médico reconozca la enfermedad del enfermo y otro que, al hacerlo, el propio médico esté contribuyendo a la enfermedad o valorando al enfermo por su disfunción. Cuando se cae en este falso temor, se prefiere negar los daños de fondo y se pone énfasis en la ausencia de males. Pero tal énfasis no puede pasar desapercibido, es digno de análisis a partir de las categorías centrales desde las cuales se llega a él.

Quizá no sea injusto decir que tanto Lerner como Badinter caen en este razonamiento circular que les impide ver el peso real del patriarcado como opresor de las mujeres, debido a lo que señala la filósofa estadounidense Catharine MacKinnon. Ella nos dice que, en general, las feministas académicas se niegan a dar peso al patriarcado porque tienen que "dar cuentas a los hombres", ya que han sido aceptadas en el poder patriarcal. En consecuencia, no pueden ver a las mujeres como víctimas, pues tendrían que reclamarles a los victimarios una justificación, y éstos las han acogido en el reino del poder. ${ }^{22}$ Al mismo tiempo, y esto es lo más evidente, tales académicas albergan el débil razonamiento de que si aceptaran la condición de víctima de las mujeres, estarían condenándolas a esta condición y contribuirían a su victimización. MacKinnon afirma:

[...] el desfile de horrores que demuestra la condición de víctimas de las mujeres con frecuencia provoca la siguiente crítica: si yo digo que las mujeres son victimizadas, estoy reforzando el estereotipo de que las mujeres "son" víctimas, lo que a su vez contribuye a su victimización. [Pero cabe preguntar] a quienes piensan que no es bueno para las mujeres pensar en sí mismas como víctimas ¿cómo puede ser bueno para nosotras negar lo que nos pasa? ${ }^{23}$

${ }^{22}$ C. MacKinnon, op. cit., p. 338.

${ }^{23}$ Idem . 


\section{Sobre la igualdad en Lerner y Badinter}

¿Pero en qué nivel se da la igualdad de mujeres y hombres afirmada por Lerner y Badinter?, ¿cómo es que tal idea las conduce a evitar el reconocimiento de la condición de víctima de la mujer en el patriarcado? En fin, ¿cómo podemos concebir al patriarcado y una liberación de él que no desconozca la realidad?

Desde luego, la idea de la igualdad interhumana es en sí misma una guía indispensable para pensar las relaciones entre los sexos y los géneros. Tenemos que partir del hecho de que nadie es más que los otros (otras). En principio, y más allá de los planteamientos de Lerner y Badinter, al pensar en las mujeres parece necesario reconocer la igualdad ontológica y ética entre las dos mitades de la humanidad: es decir, todos los humanos somos iguales en valor, capacidades y condición humana, con independencia del sexo. Pero hasta ahora, la sociedad no ha hecho real tal igualdad, ésta se ha manejado como un postulado teórico al que hay que llegar pero al que le falta mucho para ser real. Como bien dice MacKinnon, las mujeres somos seres humanos de verdad, pero no en la sociedad, ésta nos niega las condiciones de igualdad con los humanos hombres. ${ }^{24}$ Tales condiciones -según veremos- se refieren al reparto igualitario de bienes materiales, de trato público y privado, de reconocimiento y garantía de respeto a nuestra integridad física y, en fin, de la valoración de nuestro ser y capacidades.

A casi nadie se le esconde que nunca se le han dado a nuestros pensamientos, decisiones, acciones y sufrimientos, la misma importancia que a los de los hombres, nunca se nos ha otorgado "igual poder en la vida social"; las condiciones de existencia son muy distintas para cada una de las dos mitades de la humanidad. Basta con tomar en cuenta que no hay reparto igualitario de bienes materiales, la sociedad estipula sueldos superiores a los hombres; tampoco hay reconocimiento social igualitario para las mujeres y los oficios o las tareas realizadas por éstas; ni hay representatividad paritaria, las decisiones sociales las toman, en la gran mayoría de los casos, los hombres. En la palestra, en los grandes puestos, así como en muchos parlamentos de distintos países, predominan ellos y hay una minoría excepcional de ellas. ${ }^{25} \mathrm{~A}$ la vez - como advierte MacKinnon-, la violación y la violencia contra las mujeres, en lo público y lo privado, no es condenada con la misma fuerza y énfasis con que se

${ }^{24}$ C. MacKinnon, op. cit., p. 332.

${ }^{25}$ Como bien afirma Nancy Frazer, sin reparto justo, representatividad y reconocimiento, no se puede hablar de justicia social ni de mínima igualdad (N. Frazer, "Heterosexism, misrecognition, and capitalism: A response to Judith Butler", en Fortunes of Feminism, From State-Manged Capitalism to Neoliberal Crisis. Nueva York, Verso, 2013). 
condena la violación de los niños. No se nos da el mismo valor que a la mitad masculina de la humanidad. ${ }^{26}$

¿Cómo comprender y ubicar entonces la igualdad a la que se refieren Lerner y Badinter? Estas pensadoras proponen la igualdad como algo que ha ocurrido ya, sin embargo, tal ocurrir sólo se entiende (e incluso se puede aceptar) bajo el marco de los presupuestos de análisis de estas autoras: la presencia de cierta actividad de las mujeres en la historia y la innegable necesidad de tender a un futuro que signifique una real evolución para la humanidad. Podemos admitir, en cierto sentido, la idea de Lerner de que hemos participado en la historia. No hay motivo para oponerse de manera radical. Ello es verdad no sólo por el hecho elemental de que sin nosotras nada hubiera sido posible, sino también porque se nos han reconocido ciertas "virtudes" que han hecho que, a pesar de todo, el propio cristianismo - como señala Lerner, impuso al Dios padre- haya tenido que incluir a las vírgenes y respetar los rituales importantes que se les rinden. Sin la virgen María y sus sucedáneas, la religión cristiana no hubiera adquirido el poder que tiene. Incluso hay que tomar en cuenta que desde hace siglos las mujeres hemos ocupado ciertos puestos públicos: han existido reinas, emperatrices y gobernantes mujeres de diversos tipos. No obstante, nada de lo anterior indica que hayamos sido actores y agentes históricos -según afirma Lerner. Las gobernantes femeninas han sido siempre, y siguen siendo, una excepción. Asimismo, nunca se ha formado un "consejo de mujeres" que gobierne de acuerdo a decisiones comunes, siempre ha habido consejos y parlamentos formados por hombres, o por una inmensa mayoría de ellos.

Unas cuantas mujeres no redimen a todas las demás, en especial, porque los hombres siempre han buscado los modos y las condiciones para opacarnos y restarnos valía. La realidad es que el patriarcado nos ha mantenido en segundo o tercer plano. Tan sólo si nos detenemos en los símbolos cristianos (en el que se centra Lerner), resulta innegable que aunque las vírgenes tienen un lugar importante -según lo hemos señalado-, este lugar siempre ha estado a la sombra de la santísima y suprema trinidad masculina: Dios padre, Dios hijo y Dios espíritu santo. No son equivalentes la autoridad y la jerarquía masculina y la femenina.

En cuanto a la idea de igualdad basada en la evolución y el futuro previsto por Badinter, cabe notar que aunque es una idea que constituye una importante guía de la acción, se trata aún de una idea abstracta, no real, que en la mayoría de los países está quizá en las leyes, pero no se ha plasmado en reglamentos concretos que puedan hacer efectivas esas leyes. Además, tal postulado legal de igualdad carece - en la mayoría de los países- del respaldo de una cultura, una sensibilidad por parte de los jueces para hacerla real. Es posible (aunque

${ }^{26}$ Ibid., p. 73. 
no seguro) que en la Francia parisina estas deficiencias estén superadas, es posible que si se lleve a la práctica la igualdad de derechos legales y que, en efecto, las mujeres hayan llegado en general a someter a los hombres por la vía de la amenaza legal, pero no podemos conformarnos con esto para decir que el patriarcado está quedando atrás, pues mundialmente no han cambiado de manera generalizada las condiciones de reconocimiento, de reparto y de representatividad para las mujeres, de respeto a su sexualidad y consideración a su integridad por violencia o violación -incluso habría que ver si esto se da en la propia Francia.

\section{La negación de la condición de víctima de las mujeres}

En tanto la idea de igualdad se propone en un nivel abstracto, que no se contrasta con los múltiples hechos que hemos aludido al inicio de este artículo, ella puede proponerse como un logro ya realizado. Para Lerner, las mujeres han tenido en la historia las mismas condiciones que los hombres, y para Badinter, la igualdad es un postulado básico de la evolución necesaria de la humanidad. En este contexto, para ambas pensadoras es inadecuado concebirnos como víctimas porque ello impide ver lo ya logrado y de este modo nosotras mismas nos victimizamos. ¿Pero equivale el reconocimiento de la condición de víctima de las mujeres a atribuirles por fuerza una esencia tal y a sabotear con ello la lucha por la igualdad?

Parece conveniente profundizar en la distinción entre reconocerse como víctima y la actitud de victimización. Como hemos indicado más arriba, lo primero consiste en saber que se ha sufrido un daño, lo segundo en creerse siempre perjudicado sin motivo suficiente, en centrar el propio valor en ello y reclamar protección. Es cierto que varias corrientes feministas cayeron en el pasado en este tipo de "victimización". Pero desde los años setenta y ochenta del siglo Xx, diferentes voces como las de Françoise D'Eaubonne advirtieron que el feminismo debería dejar atrás toda queja sobre la situación de la mujer y ver hacia adelante y a los otros: abrirse a los problemas del mundo y a las otras desigualdades e injusticias. ${ }^{27}$ No obstante, el hecho de no victimizarnos, no implica desconocer que, de hecho, no gozamos de las mismas condiciones sociales de los hombres y que esto nos hace daño puesto que no se nos valora ni se nos toma en cuenta al mismo nivel que a ellos. Y al aceptar esta realidad no estamos reforzando ningún estereotipo, no estamos cayendo en la "minoría de edad", ni estamos reclamando protección por causa de nuestro sufrimiento.

\footnotetext{
${ }^{27}$ Françoise D'Eaubonne, Le feminism ou la mort. París, Pierre Horay, 1974, p. 10.
} 
Antes bien, se nos impone la necesidad de ver con claridad las condiciones en que desarrollamos nuestras vidas.

Por otro lado, no es deseando la igualdad o afirmándola en la teoría que ella se logra, más bien, dado que el patriarcado sigue siendo una estructura efectiva, hemos de seguir trabajando por cambiar las condiciones sociales de vida: por la verdadera igualdad en el derecho a la educación, en la percepción salarial, en la desaparición del "techo de cristal", debemos seguir advirtiendo y creando oposición a los feminicidios y a la sumisión extrema de la mujer en los países musulmanes y en cualquier región del mundo, seguir luchando por ser escuchadas y respetadas en nuestras decisiones privadas y públicas por adquirir una representatividad y reconocimiento equitativo con los hombres, y por tener el mismo valor que éstos. Mientras no acabemos con estos hechos, no podemos decir que las mujeres han sido agentes y actores de la historia y que se ha logrado la igualdad.

\section{¿Cómo liberarnos del patriarcado?}

Acabar con los hechos anteriores se presenta como una tarea inconmensurable. ¿Cómo podemos en verdad "libertarnos" del patriarcado?, ¿en qué consiste éste?

Como bien lo advierte Catharine MacKinnon, el tema de la condición de víctima de la mujer provoca inquietudes "en torno al eje tácito: libre albedrío/ determinismo". ${ }^{28}$ ¿Si aceptamos que el sistema patriarcal nos causa daño y nos convierte en víctimas quedamos acaso condenadas a él y a cederles todo el poder a los hombres?, ¿tenemos que negar toda determinación para liberarnos?, ¿cómo se juegan aquí la libertad y la determinación?

Hay que reconocer con Gerda Lerner y Élisabeth Badinter que el patriarcado se originó y reside, en principio, en la posesión sexual y reproductiva de la mujer, sin embargo, no se reduce a estos aspectos, él no se limita al ámbito de la familia patriarcal, también son propios de él -según lo han destacado, con fundamento en investigaciones arqueológicas, Erick Fromm y Marija Gimbutas- el surgimiento de la violencia destructiva, la guerra, y el afán de tener, dominar y excluir a los "débiles". ${ }^{29}$ Por tanto, el patriarcado no deja de existir porque - en algunas sociedades- la ley establezca que las mujeres pueden decidir el número de hijos y cuenten con medios médicos para hacerlo. Es verdad que ha habido muchos cambios sociales y que, sobre todo

${ }^{28}$ C. MacKinnon, op. cit., p. 338.

${ }^{29}$ Erick Fromm, Anatomía de la destructividad humana. México, Siglo XXI, 1974 y Marija Gimbutas, The Kurgans Culture and the Indo-Europeahization of Europe. Whashington, Ed. Richard Diebdol, 1997. 
en los países desarrollados, ha habido una liberación sexual y reproductiva de las mujeres (al menos en ciertas capas sociales). Pero el patriarcado se da en muchos otros aspectos y no deja de existir al contrarrestarse uno o varios de ellos, ni siquiera los que le dieron origen. En Islandia, el país que cuenta con la menor brecha de género (según los índices del Foro Económico Mundial) se ha logrado el empoderamiento político de la mujer, y una instrucción y representación política igual a la del hombre, sin embargo, después de muchos años de lucha, no se ha conquistado aún la igualdad salarial entre hombres y mujeres. ${ }^{30}$ En Suiza, según los reportes de Amnistía Internacional "Una de cada cinco mujeres ha sido golpeada, obligada por la fuerza física a mantener relaciones o sometida a algún otro tipo de abuso en la vida". ${ }^{31}$ Asimismo en Suecia, donde la mujer decide el número de hijos y donde los padres se ocupan por igual de los cuidados maternales y la educación de los hijos, no se da la colaboración de los hombres en los trabajos de la casa. ${ }^{32}$ No hay igualdad real entre hombres y mujeres.

Y es que -según lo advierte Karen Warren- el patriarcado es un sistema generalizado de jerarquías inferiorizantes, de dominio (y posesión, cabe añadir) que se da en todas las relaciones sociales porque él constituye un "marco conceptual opresivo", un enfoque general, una lente construida en la sociedad con prejuicios e ideologías heredadas, una lente a través de la cual vemos la realidad ${ }^{33}$ y que se centra en el poder de los de "arriba" frente a los de "abajo”, principalmente la mujer, pero también todos los otros concebidos como "débiles": extranjeros, homosexuales, enfermos, esclavos, niños, animales y

${ }^{30}$ Vid. http://ww w.theguardian.com/commentisfree/2014/oct/28/iceland-womenfeminist-paradise-gender-gap-pay.

31 Vid. http://www.swissinfo.ch/spa/alto-a-la-violencia-contra-las-mujeres-ensuiza/4866892 y http://www.swissinfo.ch/spa/desvalorización-de-la-mujer--inclusotambién-en-suiza/7260954. En esta última referencia se afirma: "En Suiza también hay violencia contra la mujer, como en casi cada país del mundo, e incluso, el nivel es bastante alto en comparación con otros países europeos. Las estadísticas no son muy amplias al respecto, pues sólo existen desde hace poco. Sin embargo, muestran que el tema es muy preocupante: casi uno de cada dos homicidios en Suiza ocurren dentro de la esfera familiar. Eso significa, entre comillas, que para las mujeres, la familia no es un lugar seguro".

32 Beatriz Gimeno, "El debate sobre el trabajo doméstico", en Transversales. Barcelona, núm. 20, otoño, 2010, p. 4). Gimeno apunta: "En Suiza, por ejemplo, mucho de este trabajo doméstico en las casas de la clase media no adinerada lo realizan estudiantes como manera de ganar un poco de dinero extra. Las ventajas de esta manera de entenderlo es que lo desvincula del género y de la explotación de clase sin dejar de liberar a muchas mujeres de esa doble jornada que, en todo caso, desaparecería si los hombres hicieran su parte".

${ }^{33}$ Karen Warren, Ecofeminist Phylosophy. Nueva York, Rowman \& Littlefield, 2000, p. 46. 
vegetales (la naturaleza entera). Tal enfoque se plasma en hábitos, costumbres, creencias, sentimientos, símbolos, imágenes, lenguajes verbales y corporales, temores y expectativas.

En tanto opresivo, el marco conceptual conformado por el patriarcado no sólo involucra una estructura lógica sino, ante todo, un sistema dualista de valores en el que lo tradicionalmente concebido como masculino tiene máximo valor y lo femenino un valor mínimo, y es un sistema cuyo objetivo es explicar, mantener y justificar relaciones de dominación (y posesión) injustificada de las mujeres por los hombres y de los "débiles" por los fuertes. Para ello, el patriarcado refuerza el poder y los privilegios de los segundos sobre los primeros, ${ }^{34}$ perpetúa la subordinación y le otorga "permiso moral" a esta última al presentarla como natural.

En consecuencia, el patriarcado, en tanto sistema de dominio (posesión) y jerarquía injustificada está en la estructura misma de toda nuestra organización social, en las instituciones públicas y privadas, en la manera de pensar y sentir, de hacer y padecer. Esto no significa que todos los individuos seamos patriarcales con la misma intensidad, ni tampoco que -según nos previene Élisabeth Badinter- todos los hombres sean unos machos irredentos, y las mujeres seamos seres ajenos a la violencia y a la voluntad de dominio. Los individuos podemos tomar cierta distancia crítica respecto del patriarcado. Hay hombres que no son típicamente patriarcales y mujeres que sí lo son, pues el patriarcado no es tanto un fenómeno de los individuos (aunque los involucra en mayor o menor medida) como una estructura de organización social que nos da un enfoque de las relaciones entre los géneros y los sexos. Por ello, sigue existiendo el "techo de cristal" para las mujeres, siguen valorándose como inferiores los oficios femeninos, condenándose la sexualidad femenina, cometiéndose feminicidios, y continúa también la ausencia de una representatividad social justa de las mujeres (ésta sigue siendo menor en el noventa y nueve por ciento de los países -salvo, quizá, en Islandia).

Es preciso reconocer que el patriarcado es una realidad presente y ubicua que aparece a veces aquí y otras allá, ya que reside en la estructura social misma. Tiene razón MacKinnon al decirnos que no podemos conformarnos con mirar un cambio en los síntomas de la dominación patriarcal, sino que es preciso ver cómo persiste en tanto estructura; ${ }^{35}$ una estructura de subordinación y poca valoración del cuerpo femenino, de su sexualidad, y la importancia del sufrimiento de las mujeres por esta poca valoración. Desde este punto de vista, es imposible decir - con Lerner y Badinter- que las profundas desigualdades del patriarcado quedan atrás al concebirnos como agentes activos de la historia

${ }^{34}$ Ibid., pp. 46-47.

${ }^{35}$ C. MacKinnon, op. cit., p. 11. 
y al contar con la proyección de un mejor futuro y contar, en el presente, con el respaldo de las leyes. En diferentes aspectos, todas las sociedades siguen organizadas en todas sus relaciones por el patriarcado. Éste conforma una red de factores profundamente implicados unos con otros. Marilyn Frye advierte de manera muy clara que en el patriarcado, las mujeres "vivimos como pájaros enjaulados en una serie de barrotes que, en conjunto, impiden nuestro movimiento". ${ }^{36}$ ¿Cómo encontrar la libertad?

Parece que no nos queda más que asumir el determinismo y aceptar la imposibilidad de trascender aquello que nos circunda, invade y atrapa. Sin embargo, no es así. Todo depende del tipo de libertad que concibamos: una libertad absoluta y desconocedora de la realidad, o una relativa, paradójica, que sabe que su primer y gran impulso es el reconocimiento crítico de las determinaciones y que es justo la crítica incansable, la oposición lúcida, lo que nos permite tomar una distancia y generar alternativas novedosas, portadoras de futuro. Sólo cuando nos alejamos de la jaula, dice también Marilyn Frye, podemos ver en verdad los barrotes que nos limitan y nuestro propio atrapamiento.

Es sólo cuando nos alejamos un poco y vemos uno por uno los barrotes, microscópicamente, y adquirimos una visión macroscópica de la jaula entera, que podemos ver en un instante, por qué el pájaro no va a ningún lado. Esto no requiere ningún poder mental especial. Es perfectamente obvio que el pájaro está rodeado por una red de barreras relacionadas de forma sistemática, ninguna de las cuales puede ser el impedimento definitivo para su vuelo, sino que en relación con todas las demás conforma un confinamiento tan sólido como las paredes de un calabozo. ${ }^{37}$

La visión crítica es una libertad limitada, relativa y no absoluta, pero que se niega a caer en la creencia de que al postular la igualdad entre mujeres y hombres, ella se hace real. La liberación del patriarcado no podrá darse en muchos siglos, y requerirá la transformación total de la sociedad. Para ello -según afirma MacKinnon-, hemos de afirmar la igualdad como un hecho básico, que no puede ser regateado por la dominación masculina y otorgado sólo al nivel de las leyes en la distribución del poder que hace el patriarcado para dominarnos, sino como algo que es una realidad elemental que ha de consistir en la igualdad de oportunidades, sin que la igualdad sea exaltada como un privilegio. ${ }^{38}$ También, como quiere Warren, hemos de reelaborar

\footnotetext{
${ }^{36}$ Marilyn Frye, Politics of Reality. Berkeley, Crossing Press, [1941] 1983, p. 4.

${ }^{37}$ Ibid., p. 5.

${ }^{38}$ Ibid., p. 78.
} 
los mitos, símbolos, signos, el lenguaje, la vida espiritual y la cultura entera, aunque habremos de estar conscientes de que quizá antes nos alcance la eventual hecatombe ecológica - provocada por el mismo patriarcado- según lo han asumido diversos pensadores de distintas disciplinas y posturas, ${ }^{39} \mathrm{y}$ en especial, las ecofeministas. No obstante, la lucidez de la conciencia es el mejor de los comienzos y es un signo de una resistencia fértil, sin falsas ilusiones ni parcializaciones de lo real.

${ }^{39} \mathrm{El}$ primero de estos pensadores que cabe destacar es Murray Brooklin, pero también está la futuróloga Reiner Eisler con su obra destacada The Chalise and the Balde. Harper Collins Publisher, 1987, 1995. 